\title{
Modeling of Solid-Fluid non-catalytic Processes for Nickel Ion Removal
}

\author{
GABRIELA BUEMA ${ }^{1 *}$, NICOLETA LUPU ${ }^{1}$, HORIA CHIRIAC ${ }^{1}$, GABRIELA CIOBANU ${ }^{2}$, \\ OLGA KOTOVA ${ }^{3}$, MARIA HARJA ${ }^{2 *}$ \\ ${ }^{1}$ National Institute of Research and Development for Technical Physics, 47 Prof. Dimitrie Mangeron Blvd., 700050, Iasi, \\ Romania \\ ${ }^{2}$ Gheorghe Asachi Technical University of Iasi, Faculty of Chemical Engineering and Environmental Protection, Chemical \\ Engineering Department, 73 Prof. Dimitrie Mangeron Blvd., 700050, Iasi, Romania \\ ${ }^{3}$ N. P. Yushkin Institute of Geology of the Komi Science Center of the Ural Branch of the Russian Academy of Sciences, \\ Pervomayskaya st. 54, 167982, Syktyvkar, Russia
}

\begin{abstract}
The aim of this study is modeling of the process of Ni(II) removal onto new materials synthesized by a facile coprecipitation method. The literature presents different surfactants intercalated on MgAl-LDH with applicability for nickel ions removal, but the researches on the use of this material "as cast" as adsorbent for Ni(II) ions are limited, it is reason to develop this study. The morphology, chemical composition, and the basic structure of the new material were analyzed by SEM, EDAX, BET, XRD and FT-IR. The kinetic modeling was performed using the pseudo-first-order, four-type linear pseudo-second-order, and intraparticle diffusion. The experimental data demonstrated that the adsorption process is very fast in the first 20 minutes and reach equilibrium after 50 min. The maximum adsorption capacities of the adsorbent are in the range of $36.5-68.18 \mathrm{mg} / \mathrm{g}$, for the 200-500 $m g / L$ initial solution concentration.
\end{abstract}

Keywords: adsorption, kinetics, MgAl-LDH, modeling, nickel ions

\section{Introduction}

Contamination of water with heavy metals is a recognized problem in many countries [1, 2]. The presence of heavy metals in the industrial wastewater has a serious environmental impact over aquatic life and humans. It is unanimous accepted that heavy metals and dyes has a strong impact on the environment [3-8].

The most common heavy metal pollutants from water are mercury, cadmium, arsenic, chromium, nickel, lead, zinc, iron, and selenium. Among the different heavy metals known (copper, lead, cobalt, zinc, chrome, uranium), Ni(II) occupies a special place. The nickel, a known heavy metal is found in the environment, because is large used in industry $[9,10]$, in production, recycling and disposal leading to widespread environmental pollution. The nickel pollution can be caused by various industrial processes, such as incinerators, rubber/plastic industries, battery industries, electroplating industries. The nickel can produce free radicals that induced pathophysiological changes in living systems. On the other hand the nickel ions induced genotoxicity, carcinogenicity, immunotoxicity, etc. [11].

The most used methods for heavy metal removal is adsorption, the adsorption process has been involved for treatment of contaminated water, because is a cheap and convenient method as compared with various techniques [4, 12-14]. So far, certain materials have been used to retain this type of pollutant using adsorption process: Layered double hydroxides (LDH) [15, 16], Chitosan Coated Cobalt Ferrite [14]; Biochars produced from wheat straw pellets and rice husk [17]; Peat [18]; Adsorbents from fly ash [2, 19]; Natural zeolite [20]; Natural, Sodium and Acid Modified Clinoptilolite-Rich Tuff [1]; Modified zeolite [21], sawdust [22].

*email: gbuema@phys-iasi.ro; mharja@tuiasi.ro 
LDH is known as anionic clays, and are extensively studied in the last period due to their properties $[23,24]$. LDHs have positively charged layers and water molecules between the layers. The general formula of $\mathrm{LDH}$ is $\left[\mathrm{M}(\mathrm{II})_{1-\mathrm{x}} \mathrm{M}(\mathrm{III})_{\mathrm{x}}(\mathrm{OH})_{2}\right]_{\mathrm{x}}+\left(\mathrm{A}^{\mathrm{n}-}\right)_{\mathrm{x} / \mathrm{n}} \cdot \mathrm{m} \mathrm{H}_{2} \mathrm{O}$, where $\mathrm{M}(\mathrm{II})$ and $\mathrm{M}(\mathrm{III})$ are di- and trivalent metals respectively, and $\mathrm{A}^{\mathrm{n}-}$ is an anion. The positive charges produced from the isomorph substitution of divalent or trivalent cations, are hostage balanced by anions [25].

A variety of layered materials have been synthesized by different methods: coprecipitation, ionexchange, rehydration, hydrothermal, secondary intercalation, re-coprecipitation, among these the coprecipitation is extensively used, because a wide variety of anionic species can directly intercalate between the hydroxylated sheets [26]. The LDHs have widespread applications as catalyst precursors, adsorbents, anionic exchangers, in biochemistry, polymer additives, as hybrid pigments, etc. [27, 28].

In the present study, MgAl-LDH was prepared and checked for its potential in removing $\mathrm{Ni}(\mathrm{II})$ from aqueous solution. Another objective was the kinetics modeling using the Pseudo-first-order, Four-type linear pseudo-second-order, and Intraparticle diffusion kinetic models.

\section{Materials and methods}

\subsection{Materials synthesis and characterization}

The chemical reagents were analytical grade and were used as received. $\mathrm{Mg}\left(\mathrm{NO}_{3}\right)_{2} \cdot 6 \mathrm{H}_{2} \mathrm{O}$, $\mathrm{Al}\left(\mathrm{NO}_{3}\right)_{3} \bullet 9 \mathrm{H}_{2} \mathrm{O}, \mathrm{NaOH}$ and $\mathrm{Na}_{2} \mathrm{CO}_{3}$ were used for the synthesis of the MgAl-LDH.

For preparing solution having concentrations of 200-500 mg/L, was used $\mathrm{Ni}\left(\mathrm{NO}_{3}\right)_{2} \bullet 6 \mathrm{H}_{2} \mathrm{O}$, diluted in $0.5 \mathrm{~L}$ deionized water. The $0.1 \mathrm{M} \mathrm{HNO}_{3}$ solution was added to adjust the initial solution $p \mathrm{H}$. All chemicals used in this research were purchased from Merck and were utilized without any purification.

The adsorbent, MgAl-LDH, (Mg/Al ratio of 2/1) was synthesized by coprecipitation method [29], with some modifications, as follows: $\mathrm{Mg}\left(\mathrm{NO}_{3}\right)_{2} \cdot 6 \mathrm{H}_{2} \mathrm{O}\left(0.126\right.$ mole, 32.3g) and $\mathrm{Al}\left(\mathrm{NO}_{3}\right)_{3} \cdot 9 \mathrm{H}_{2} \mathrm{O}$ $(0.063$ mole, $23.63 \mathrm{~g})$ were dissolved in $250 \mathrm{~mL}$ of deionized water. The $\mathrm{NaOH}(0.6 \mathrm{M})$ and $\mathrm{Na}_{2} \mathrm{CO}_{3}$

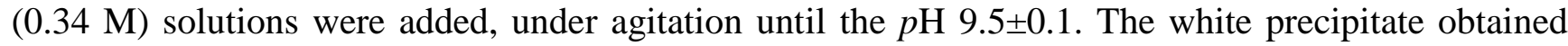
indicated the formation of the proposed adsorbent. The suspension was stirred at $65{ }^{\circ} \mathrm{C}$, for $12 \mathrm{~h}$. The suspension was filtered, repeatedly washed to $p \mathrm{H} 7$ and dried at $60^{\circ} \mathrm{C}$ for $24 \mathrm{~h}$.

A scanning electron microscope (JEOL JSM-6390) equipped with an EDS detector was used for morphology characterization. The elemental analysis was determined using energy dispersive electron microscopy (SEM-EDX). BET surface area was determined by Quantachrome instruments, Nova 2200e model. X-ray diffraction (XRD) pattern of the sample was characterized by using an Advance D8-Bruker X-ray diffractometer, with $\mathrm{Cu}-\mathrm{K} \alpha$ radiation. The samples were scanned at $10^{\circ}-60^{\circ}$. FTIR spectrum was obtained using a Jasco FT/IR-6100 spectrometer, the samples were scanned between 400 and $4000 \mathrm{~cm}^{-1}$.

\subsection{Adsorption studies}

Some researchers have shown through their papers that the optimal initial solution $p \mathrm{H}$ for nickel adsorption is 6 , regardless of the adsorbent used [10, 30, 31]. Consequently, the batch equilibrium experiments were carried out at constant $p \mathrm{H}$ value of $6.0 \pm 0.1$, using $40 \mathrm{mg}$ of $\mathrm{MgAl}-\mathrm{LDH}$ and $40 \mathrm{~mL}$ of $\mathrm{Ni}(\mathrm{II})$ solution having different initial concentrations $(200,300,500 \mathrm{mg} / \mathrm{L})$. Also, it should be mentioned that the quantity of the adsorbent dose was established based on some preliminary studies [10].

The Ni(II) concentration in the supernatant was analyzed by EDTA complexometric method that is a simple and convenient method with high precision and accuracy. Also, this method complies with the heavy metal determination norm. The laboratory tests were evaluated at room temperature under magnetic stirring at $200 \mathrm{rpm}$. All determinations were realized in duplicate.

The adsorption capacity, $\mathrm{q}(\mathrm{mg} / \mathrm{g})$ was calculated through equations (1):

$$
\boldsymbol{q}=\frac{\left(C_{0}-C_{e}\right) V}{m}
$$


where $\mathrm{C}_{0}$ and $\mathrm{C}_{\mathrm{e}}$ are the initial and equilibrium $\mathrm{Ni}(\mathrm{II})$ concentrations $(\mathrm{mg} / \mathrm{L}), \mathrm{q}$ is the amount of $\mathrm{Ni}$ (II) adsorbed onto MgAl-LDH (mg/g), $\mathrm{V}$ is the volume of $\mathrm{Ni}(\mathrm{II})$ solution (L), and $\mathrm{m}$ is the quantity of $\mathrm{MgAl}-\mathrm{LDH}(\mathrm{g})$.

\section{Results and discussions}

\subsection{Material characterization}

The morphology, chemical composition, and the basic structure of the material were analyzed by SEM, EDAX, BET, XRD and FT-IR prior to adsorption studies. A comprehensive characterization of sample is important for the possible applications in different areas. The morphology and chemical composition of sample was observed by SEM and EDX analysis. The analysis of the material is presented in Figure 1. The analysis from the SEM point of view (Figure 1) at higher magnification, allow the remark of an undoubtedly LDHs morphology [23, 28]. The overall results of analysis demonstrate that a well-organized structure was obtained under the applied synthesis conditions. SEM analysis demonstrates that the sample showed the characteristics of hexagonal platelets where the particles are interconnected with each other.

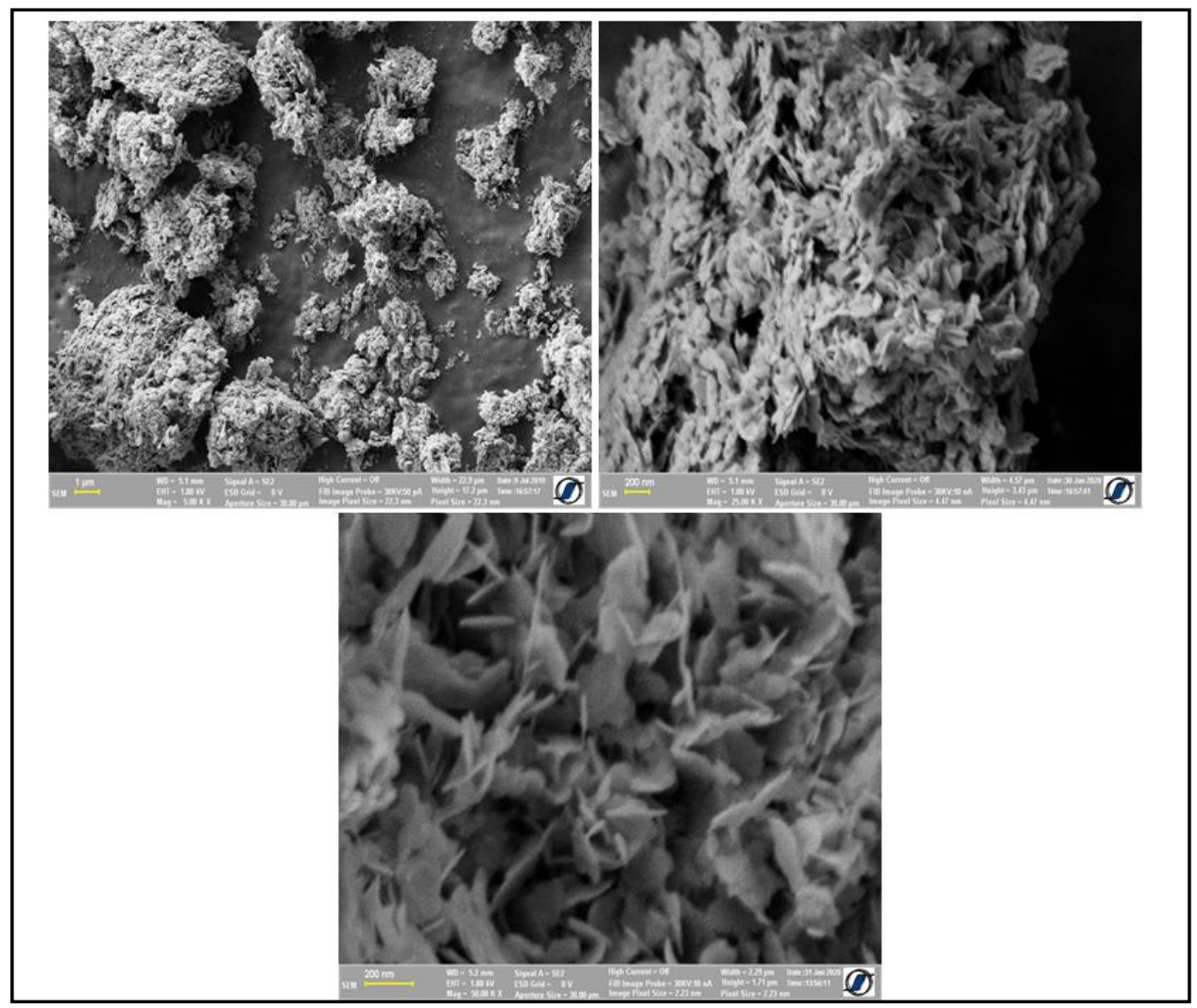

Figure 1. SEM analysis for synthesized materials

The ratio of $\mathrm{Mg} / \mathrm{Al}$ is an important criterion for characterizing material compounds. The EDS analysis showed that the structure of the material is composed of $\mathrm{Mg}, \mathrm{Al}, \mathrm{C}$, and $\mathrm{O}$. The measured $\mathrm{Mg} / \mathrm{Al}$ ratio is 2.32 , which is close to the ratio that was set out at the beginning of the synthesis. The results of the EDX analysis indicate that the carbon content of the sample is $23.18 \%$. Energy dispersive X-ray spectroscopy (EDX) is confirmed on the basis of $\mathrm{Mg} / \mathrm{Al}$ ratio that the material was successfully synthesized (Figure 2) [32]. 


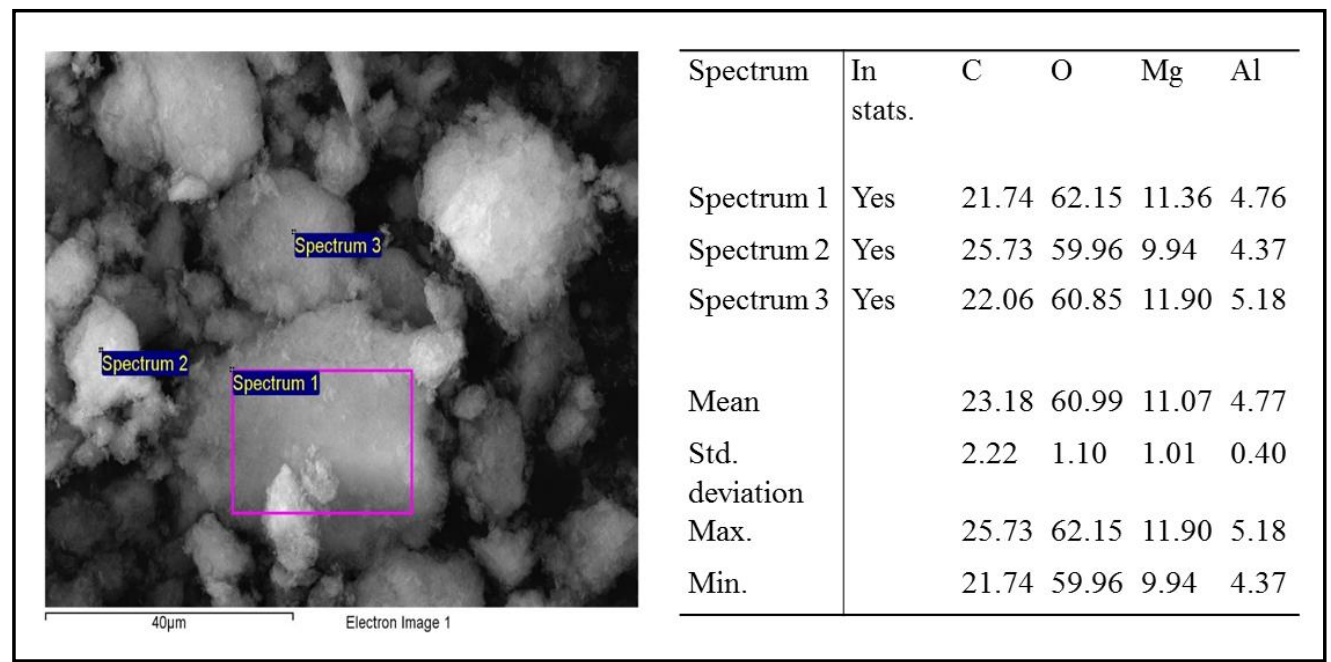

Figure 2. EDX analysis for synthesized materials

Figure 3 displays the $\mathrm{N}_{2}$ adsorption-desorption isotherms. The material presents a typical II isotherm. The specific surface area is $380 \mathrm{~m}^{2} / \mathrm{g}$. Total pore volume is $0.104 \mathrm{~cm}^{3} / \mathrm{g}$ and average pore diameter of $7.65 \mathrm{~nm}$.

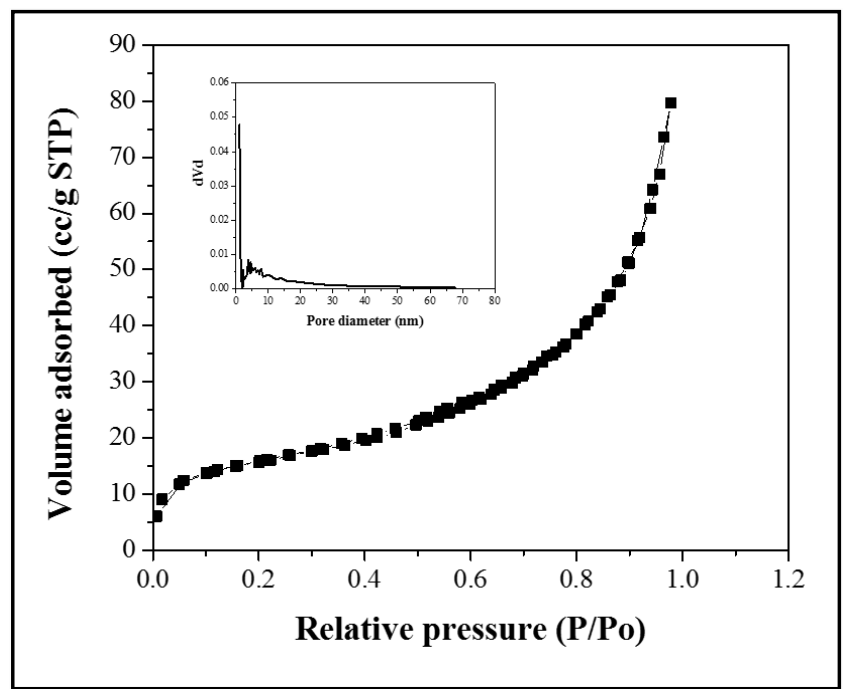

Figure 3. $\mathrm{N}_{2}$ adsorption-desorption isotherms

In order to establish the functional groups, the sample was characterized by FTIR technique.The results of FTIR analysis are presented in figure 2. Also, based on the FTIR analysis presented in figure 4 it can be stated that a MgAl-LDH type material was obtained [24, 26].

The band at $3453.68 \mathrm{~cm}^{-1}$ could be attributed to the stretching vibration of the hydroxyl group. The low intensity band at $1595.81 \mathrm{~cm}^{-1}$ is assigned to bending vibration of strongly adsorbed water (solvation water for compensating anion vibration). The band at $1371 \mathrm{~cm}^{-1}$ is assigned to carbonate vibration, the bands at 676 is due to $\mathrm{M}-\mathrm{O}$ vibration. The FTIR spectrum confirms the formation of MgAl-LDH material.

To certify the formation of MgAl-LDH, the sample was characterized by XRD analysis. The XRD patterns of the synthesized material are presented in Figure 5. 


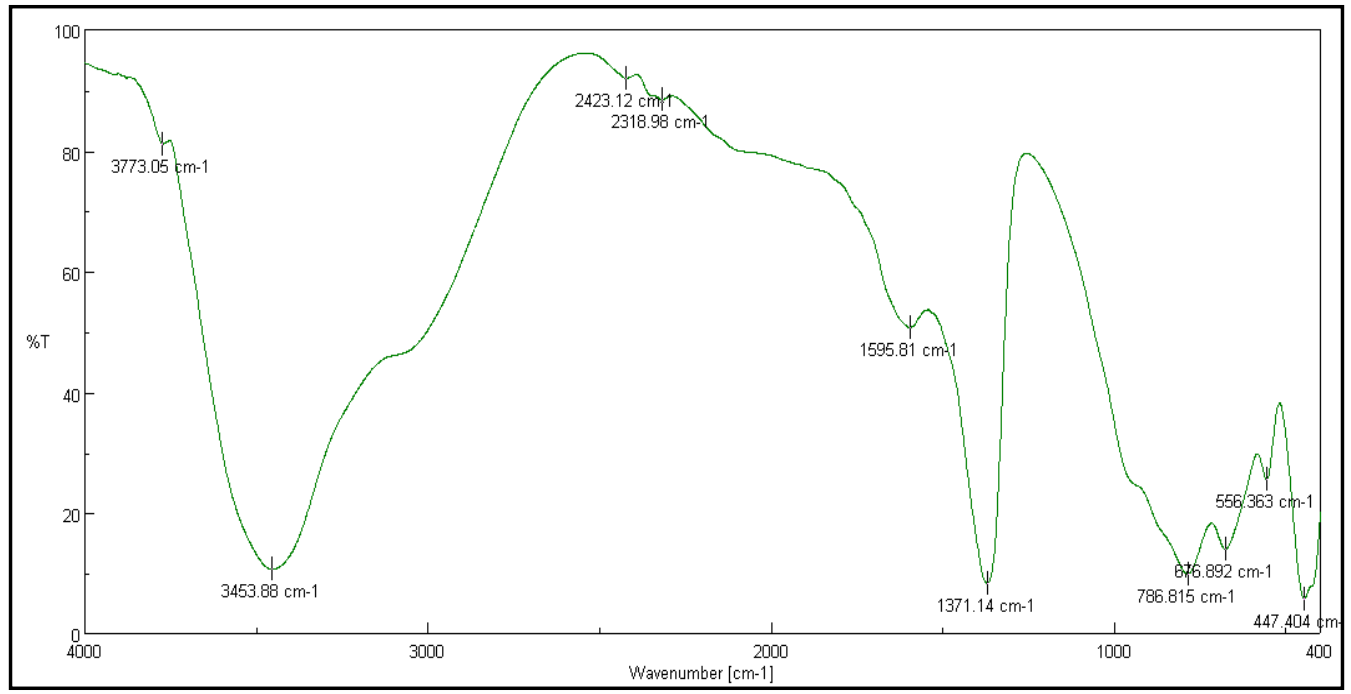

Figure 4. FTIR analysis

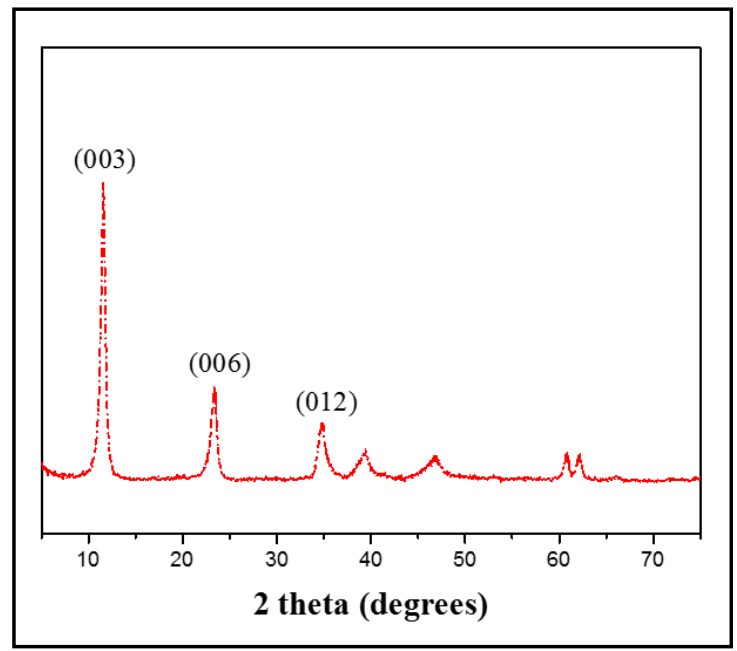

Figure 5. XRD analysis

XRD diffractogram for the LDH compounds show sharp, symmetric, and intense at low $2 \theta$ values and less intense at higher $2 \theta$ values. The peak with the major intensity was obtained at $2 \theta=11.5^{\circ}$ which corresponded to the (003) plane. The doublet peak at a $60^{\circ}$ of $2 \theta$ value indicates the existence of an ordered layered material (JCPDS File No. 22-700). The (003), (006), (012) peaks highlights the characteristics planes that can be identify in the structure of a standard MgAl-LDH synthesized material. Consequently, Figure 5 is the typical pattern of MgAl-LDH composite.

Using the overall results generated through SEM, EDX, FTIR, XRD, and BET analysis, it could be highlights that a MgAl-LDH type material was achieved.

\subsection{Adsorption results}

The experiments were developed to study the adsorption of $\mathrm{Ni}$ (II) onto synthesized adsorbent in terms of the influence of contact time. Adsorption of $\mathrm{Ni}$ (II) onto prepared material as a function of contact time for three different concentrations of Ni(II): 200, 300, and $500 \mathrm{mg} / \mathrm{L}$ is shown in Figure 6.

The adsorption process was performed for $360 \mathrm{~min}$ in order to determine the time required to obtain the maximum adsorption capacity. 


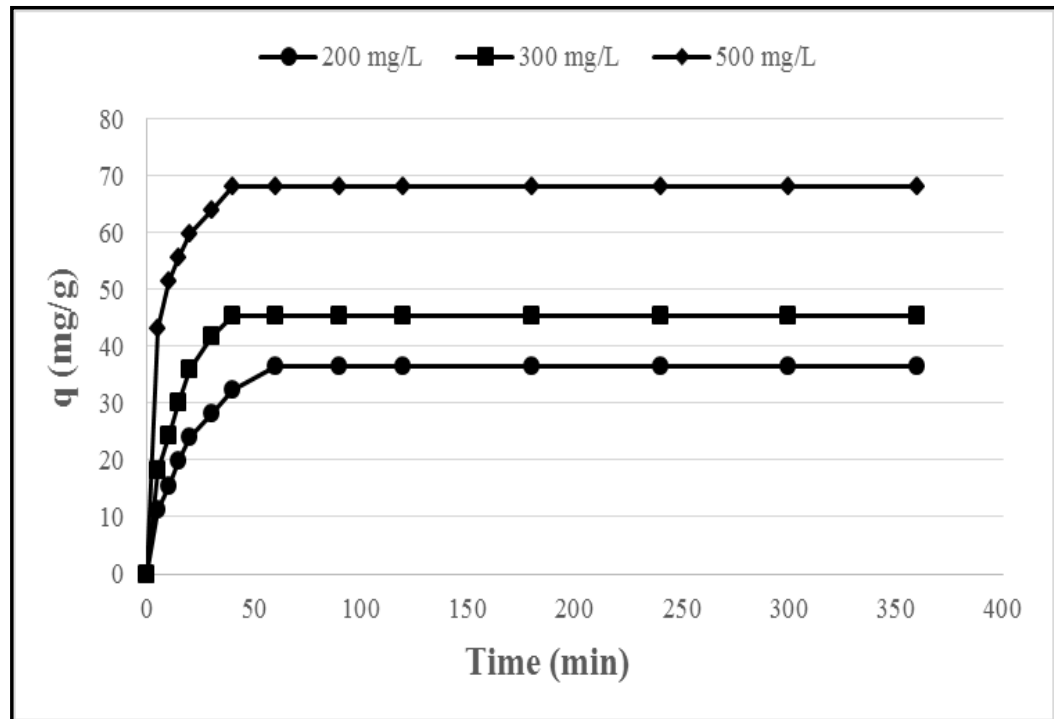

Figure 6. Effect of contact time

The results demonstrate that the adsorption capacity increased quickly within the first 20 min of contact, then rises slowly and reaches the maximum uptake after $60 \mathrm{~min}(\mathrm{q}=36.5,45.27$, respectively $68.18 \mathrm{mg} / \mathrm{g}$ at equilibrium using 200,300, and $500 \mathrm{mg} / \mathrm{L}$ initial $\mathrm{Ni}(\mathrm{II})$ concentration). Increasing the adsorption capacity with the increasing of contact time is similar for MgAl-LDH for all three working concentrations. The large number of adsorption sites available for adsorption and the rapid diffusion of metal from the solution to the external surfaces of $\mathrm{Mg}-\mathrm{Al}-\mathrm{LDH}$ contributes the fast removal rate.

Taking into account that there was no any significant change after $60 \mathrm{~min}$, an adsorption time of 60 min will be selected for further investigations. The influence of the contact time through the adsorption process confirms that the adsorption capacity is dependent on the contact time.

The results are in accord with references, a comparison is presented in Table 1.

Table 1. Comparison with literature data

\begin{tabular}{ccc}
\hline Adsorbent & Adsorption capacity, mg/g & References \\
\hline Mg-Al-Zn mingled oxides & 70.4 & {$[25]$} \\
\hline LDH-Nitrilotriacetate Composite & 7.153 & {$[27]$} \\
\hline Fly ash zeolites & 23.24 & {$[10]$} \\
\hline Ca-Fe/LDH-Cit & 2.26 & {$[33]$} \\
\hline MgAl-CO $3-L D H$ & 23.47 & {$[34]$} \\
\hline MgAl-EDTA-LDH & 108.2 & {$[35]$} \\
\hline Activated carbon & 11.9 & {$[36]$} \\
\hline C-phenylcalix[4]pyrogallolarene & 16.86 & {$[37]$} \\
\hline Cloisite Na ${ }^{+}$clay & 31.43 & {$[38]$} \\
\hline Mixture algae & 9.848 & {$[39]$} \\
\hline FGC & 12.24 & This work
\end{tabular}

The presented results confirm the effectiveness of adsorption of the $\mathrm{Ni}$ (II) ions onto MgAl-LDH material.

\subsection{Adsorption modeling}

To determine the mechanism and rate-control steps in the Ni(II) adsorption process, for the beginning, three common kinetics models, namely: the pseudo-first-order, pseudo-second-order, and 
intraparticle diffusion have been employed to fit the experimental data [40]. The linear form corresponding to each model is presented based on Eq (2), Eq (3), and Eq (4):

Pseudo-first order model:

$$
\log \left(q_{e}-q_{t}\right)=\log q_{e}-\frac{\left(k_{1} t\right)}{2.303}
$$

Pseudo-second order model:

Intraparticle diffusion model

$$
\frac{t}{q_{t}}=\frac{1}{k_{2} q_{e}{ }^{2}}+\frac{t}{q_{e}}
$$

$$
q_{t}=k_{i} t^{0.5}
$$

in which, $q_{t}(\mathrm{mg} / \mathrm{g})$ is the amount of $\mathrm{Ni}(\mathrm{II})$ ions adsorbed at time $t, q_{e}(\mathrm{mg} / \mathrm{g})$ is the amount of $\mathrm{Ni}(\mathrm{II})$ ions adsorbed at equilibrium, $k_{1}$ is the pseudo-first-order rate constant $\left(1 / \mathrm{min}\right.$.), $k_{2}$ is the pseudosecond-order rate constant $(\mathrm{g} / \mathrm{mg} \mathrm{min}) ; k_{i}$ is the intraparticle diffusion rate constant.
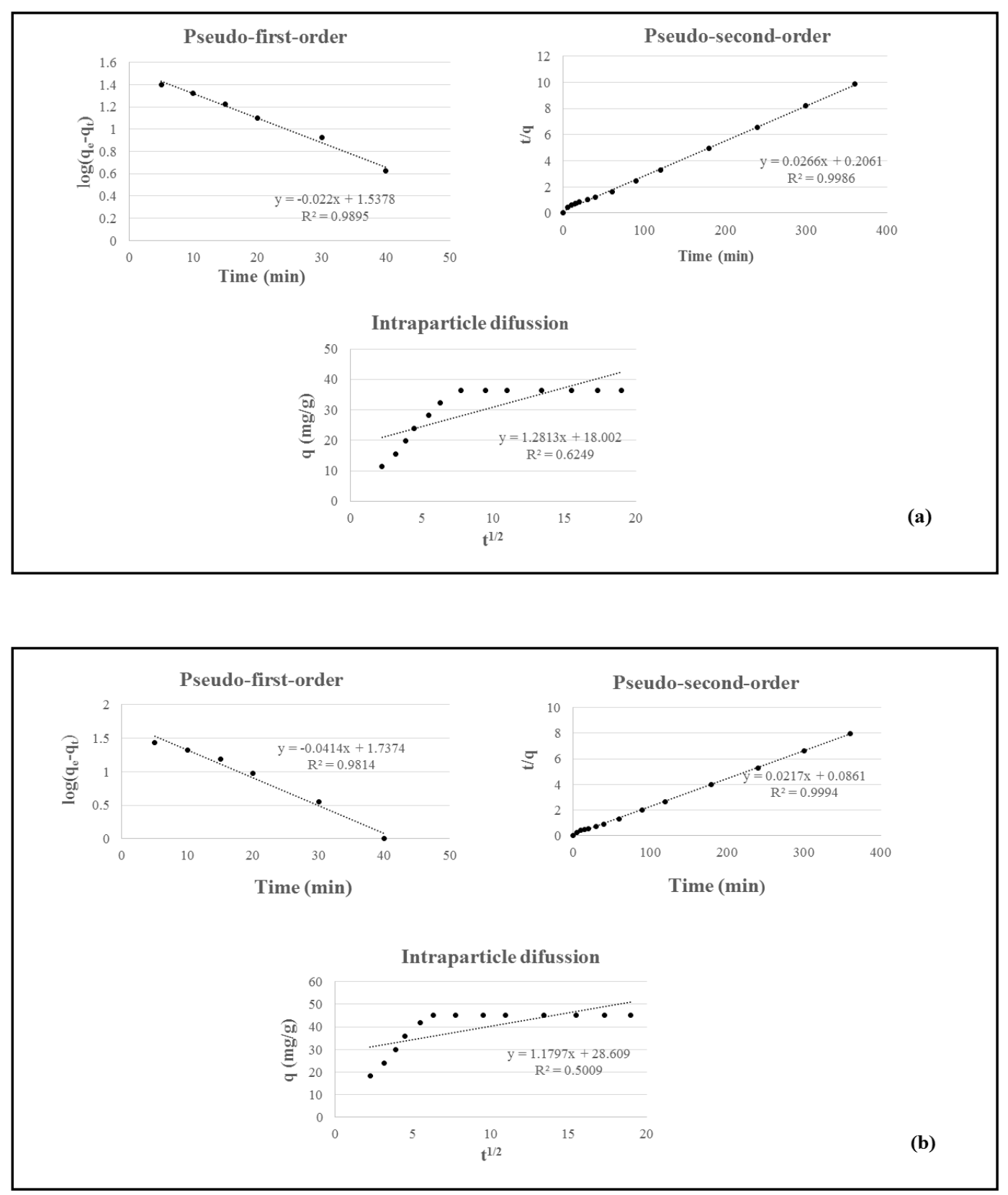


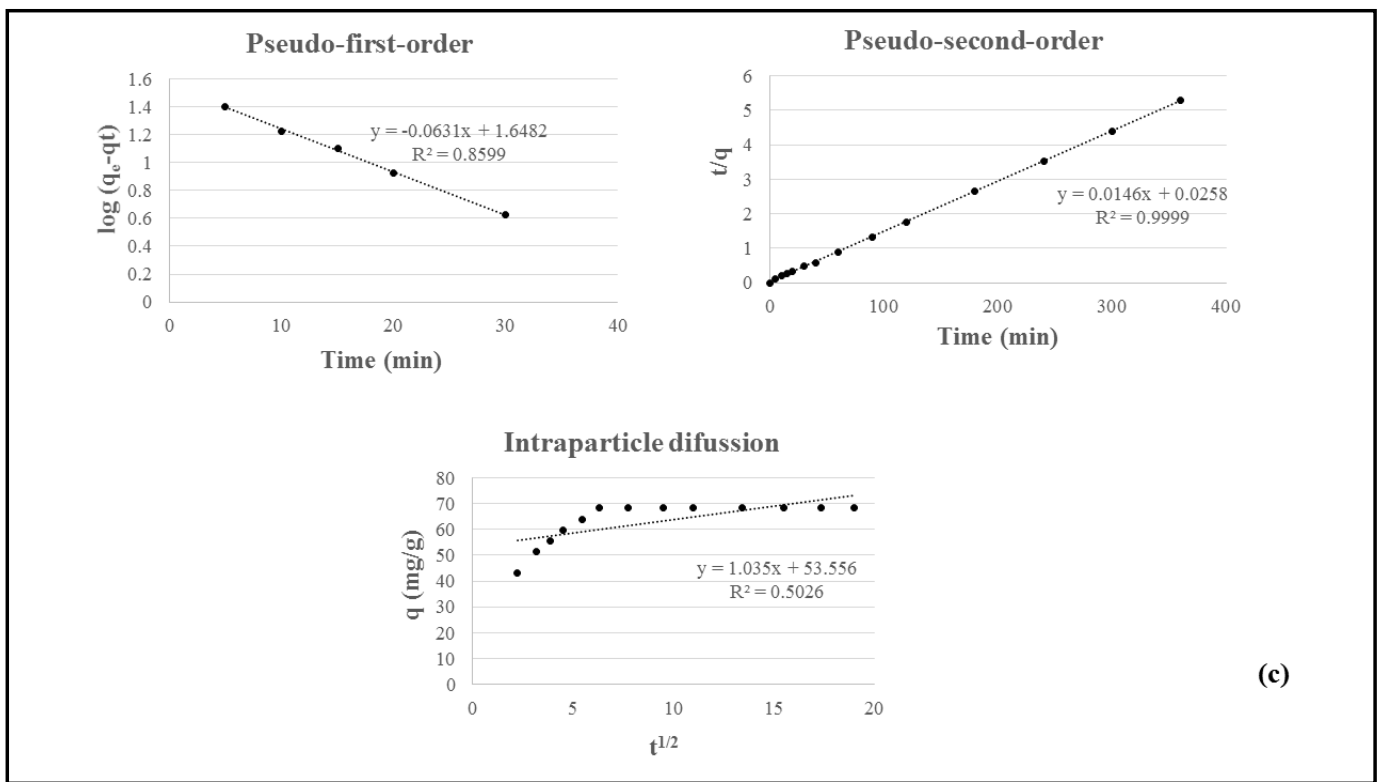

Figure 7. Pseudo-first-order model; Pseudo-second-order model; Intraparticle diffusion model for the adsorption of $\mathrm{Cd}^{2+}$ ions: (a) $200 \mathrm{mg} / \mathrm{L}$; (b) $300 \mathrm{mg} / \mathrm{L}$; (c) $500 \mathrm{mg} / \mathrm{L}$

The relevant kinetic parameters of the models are recorded in Table 2.

Table 2. Kinetic parameters of Ni(II) adsorption onto MgAl-LDH

\begin{tabular}{ccccc}
\hline \multirow{2}{*}{ Kinetic model } & Parameters & \multicolumn{3}{c}{ Values } \\
\cline { 2 - 4 } & $k_{1}, 1 / \mathrm{min}$ & $200 \mathrm{mg} / \mathrm{L}$ & $300 \mathrm{mg} / \mathrm{L}$ & $500 \mathrm{mg} / \mathrm{L}$ \\
\hline \multirow{2}{*}{ Pseudo-first order } & $R^{2}$ & 0.0506 & 0.0953 & 0.1453 \\
\cline { 2 - 4 } & $\mathrm{q}_{\mathrm{e} \mathrm{cal}}, \mathrm{mg} / \mathrm{g}$ & 37.59 & 0.9814 & 0.8599 \\
\hline \multirow{2}{*}{$\begin{array}{c}k_{2}, \mathrm{~g} / \mathrm{mg} \cdot \mathrm{min} \\
\mathrm{R}^{2}\end{array}$} & 0.0034 & 0.005 & 68.49 \\
\cline { 2 - 4 } $\begin{array}{c}\text { Intraparticle } \\
\text { diffusion }\end{array}$ & $k_{i}, \mathrm{mg} / \mathrm{g} \cdot \mathrm{min}^{0.5}$ & 0.9986 & 0.9994 & 0.0082 \\
\cline { 2 - 4 } & $\mathrm{R}^{2}$ & 0.6249 & 1.2813 & 0.9999 \\
\hline
\end{tabular}

Comparing the correlation coefficients of all kinetic models, it is obvious that the pseudo-secondorder model is suitable for the adsorption kinetic for $\mathrm{Ni}(\mathrm{II})$ onto MgAl-LDH. This model reveals that the rate-limiting step is chemical adsorption [41].

The pseudo-second-order kinetic model has been linearized into four different types (Table 3).

Table 3. Pseudo-second-order kinetic model linear forms [19]

\begin{tabular}{cccc}
\hline Type & \multicolumn{1}{c}{ Linear form } & Plot & Parameter \\
\hline Type I & $\frac{1}{q_{t}}=\frac{1}{k q_{e}^{2}}+\frac{1}{q_{e}} t$ & $\frac{t}{q_{t}} v s t$ & $\begin{array}{c}\mathrm{qe}=1 / \mathrm{m} \\
\mathrm{k}=\mathrm{m}^{2} / \mathrm{c}\end{array}$ \\
\hline Type II & $\frac{1}{q_{t}}=\left(\frac{1}{k q_{e}^{2}}\right) \frac{1}{t}+\frac{1}{q_{e}}$ & $\frac{1}{q_{t}} v s \frac{1}{t}$ & $\begin{array}{c}\mathrm{q}_{\mathrm{e}}=1 / \mathrm{c} \\
\mathrm{k}=\mathrm{c}^{2} / \mathrm{m}\end{array}$ \\
\hline Type III & $q_{t}=q_{e}-\left(\frac{1}{k q_{e}^{2}}\right) \frac{q_{t}}{t}$ & $q_{t} v s \frac{q_{t}}{t}$ & $\begin{array}{c}\mathrm{q}_{\mathrm{e}}=\mathrm{c} \\
\mathrm{k}=-1 / \mathrm{c} \mathrm{m}\end{array}$ \\
\hline Type IV & $\frac{q_{t}}{t}=k q_{e}^{2}-k q_{e}^{2} q_{t}$ & $\frac{q_{t}}{t} v s q_{t}$ & $\mathrm{qe}=-\mathrm{c} / \mathrm{m}$ \\
$\mathrm{k}=\mathrm{m}^{2} / \mathrm{c}$
\end{tabular}

The values of the pseudo-second-order model constant, $\mathrm{k}$, and the amount of the $\mathrm{Ni}$ (II) adsorbed at equilibrium, qe, are listed in Table 4. 
Table 4. Pseudo-second-order kinetic parameters obtained from the linear forms (Type I-Type IV)

\begin{tabular}{|c|c|c|c|c|}
\hline \multirow[t]{2}{*}{ Kinetic model } & \multirow{2}{*}{ Parameters } & \multicolumn{3}{|c|}{ Values } \\
\hline & & $200 \mathrm{mg} / \mathrm{L}$ & $300 \mathrm{mg} / \mathrm{L}$ & $500 \mathrm{mg} / \mathrm{L}$ \\
\hline \multirow[t]{3}{*}{ Type I } & $q_{e}(\mathrm{mg} / \mathrm{g})$ & 37.59 & 46.08 & 68.49 \\
\hline & $k(\mathrm{~g} / \mathrm{mg} \min )$ & 0.0034 & 0.0054 & 0.0082 \\
\hline & $\mathrm{R}^{2}$ & 0.9986 & 0.9994 & 0.9999 \\
\hline \multirow[t]{3}{*}{ Type II } & $q_{e}(\mathrm{mg} / \mathrm{g})$ & 39.52 & 49.02 & 69.93 \\
\hline & $k(\mathrm{~g} / \mathrm{mg} \min )$ & 0.0019 & 0.0023 & 0.0044 \\
\hline & $\mathrm{R}^{2}$ & 0.9804 & 0.972 & 0.9789 \\
\hline \multirow[t]{3}{*}{ Type III } & $q_{e}(\mathrm{mg} / \mathrm{g})$ & 39.89 & 48.74 & 69.99 \\
\hline & $k(\mathrm{~g} / \mathrm{mg} \min )$ & 0.0019 & 0.0025 & 0.0044 \\
\hline & $\mathrm{R}^{2}$ & 0.9302 & 0.8964 & 0.9599 \\
\hline \multirow[t]{3}{*}{ Type IV } & $q_{e}(\mathrm{mg} / \mathrm{g})$ & 40.65 & 49.82 & 70.28 \\
\hline & $k(\mathrm{~g} / \mathrm{mg} \min )$ & 0.0017 & 0.0022 & 0.0042 \\
\hline & $\mathrm{R}^{2}$ & 0.9302 & 0.8964 & 0.9599 \\
\hline
\end{tabular}

By comparing the results obtained for the calculated $q_{e}$, it can be noted that there are obtain approximately the same values with small differences, but the $\mathrm{R}^{2}$ value of Linear Type 1 was the highest, which means that this version is the best model to represent the $\mathrm{Ni}$ (II) adsorption on adsorbent at concentrations studied. Linear Type 1 equation is the most popular used form of the pseudo-secondorder model. Also, it must be mentioned that this linear form has been used to describe the kinetic properties of different adsorption processes [42]. The results are in agreement with the other studies [9, $18]$.

\section{Conclusions}

In this study the modeling of the process for adsorption of $\mathrm{Ni}(\mathrm{II})$ ions was performed using $\mathrm{MgAl}-$ LDH material as the adsorbent. For this study, the following conclusions can be illustrated:

- MgAl-LDH material was successfully synthesized through co-precipitation method.

- The results obtained through different characterization methods, such as: SEM, EDX, XRD and FTIR analysis highlights that the material was well synthesized.

- The adsorption capacity of $\mathrm{Ni}(\mathrm{II})$ ions increases with contact time in the first $20 \mathrm{~min}$.

- The adsorption process was studied at different time intervals, at 200, 300, and $500 \mathrm{mg} / \mathrm{L} \mathrm{Ni}(\mathrm{II})$ initial concentration. The maximum adsorption capacities of adsorbent are in the range of 36.5-68.18 $\mathrm{mg} / \mathrm{g}$ when the concentration varies within a range of $200-500 \mathrm{mg} / \mathrm{L}$.

- BET analysis showed that synthesized MgAl-LDH possessed a surface area of $380 \mathrm{~m}^{2} / \mathrm{g}$, which could show its contribution to a high adsorption capacity.

- The adsorption process is described by the pseudo-second order model.

- By comparing the values of the correlation coefficient, $\mathrm{R}^{2}$, obtained for all tested kinetic models, pseudo second-order (Linear Type I) is suitable to describe the rate kinetic data of $\mathrm{Ni}$ (II) ions on MgAl-LDH adsorbent.

The main advantage of using of MgAl-LDH material is, first of all, the easy preparation, with low costs. The overall results demonstrate the potential application of MgAl-LDH material in the adsorption process of $\mathrm{Ni}(\mathrm{II})$, with proper absorption capacities, which is essential in the wastewater treatment.

Acknowledgments: This work is funded by the UEFISCDI Agency trough Project PN-III- P1-1.2PCCDI-2017-0152 (Contract No. 75PCCDI/2018) 


\section{References}

1.ABATAL, M., OLGUIN, M.T., ABDELLAOUI, Y., EL BOUARI, A., Sorption of Cd(II), Ni(II) and Zn(II) on natural, sodium-, and acid-modified clinoptilolite-rich tuff, Environ. Prot. Eng., 44(1), 2018, 41-59. DOI: 10.5277/epe180104.

2.NOLI, F., BUEMA, G., MISAELIDES, P., HARJA, M., New materials synthesized from ash under moderate conditions for removal of toxic and radioactive metals, J. Radioanal. Nucl. Chem., 303(3), 2015, 2303-2311.

3.AYAWEI, N., ANGAYE, S.S., WANKASI, D., DIKIO, E.D., Synthesis, Characterization and Application of $\mathrm{Mg} / \mathrm{Al}$ Layered Double Hydroxide for the Degradation of Congo Red in Aqueous Solution, Open J. Phys. Chem., 5(3), 2015, 56-70.

4.BACIOIU, I.G., STOICA, L. CONSTANTIN, C., STANESCU, A.M., Adsorption Equilibrium and Kinetics Modeling for Tartrazine (E102) -Fe(II) Based Adsorbent System, Rev. Chim., 67(12), 2016, 2391-2395.

5.CULITA, D.C., SIMONESCU, C.M., PATESCU, R.E., STANICA, N., Chitosan-based Magnetic Composites - Efficient Adsorbents for Removal of $\mathrm{Pb}$ (II) and $\mathrm{Cu}$ (II) from Aqueous Mono and Bicomponent Solutions, Rev. Chim., 70(6), 2019, 2323-2330.

6.GROVER, A., MOHIUDDIN, I., MALIK, A.K., AULAKH, J.S., KIM, K.H., Zn-Al layered double hydroxides intercalated with surfactant: Synthesis and applications for efficient removal of organic dyes, J. Clean. Prod., 240, 2019, 118090.

7.SIMIONESCU, C.M., MELINESCU, A., CIUCA, M., ZARNESCU, B., Removal of Copper(II) Ions from Aqueous Solutions by Hydroxyapatite-Based Materials Prepared from Eggshells, Rev. Chim., 70(6), 2019, 1897-1902.

8.HARJA, M., BUEMA, G., BULGARIU, L., BULGARIU, D., SUTIMAN, D. M., CIOBANU, G., Removal of cadmium (II) from aqueous solution by adsorption onto modified algae and ash, Korean $J$ Chem. Eng., 32(9), 2015, 1804-1811.

9.DEHGHANI, M.H, SARMADI, M., ALIPOUR, M.R., SANAEI, D., ABDOLMALEKI, H., AGARWAL, S., GUPTA, V.K., Investigating the equilibrium and adsorption kinetics for the removal of $\mathrm{Ni}$ (II) ions from aqueous solutions using adsorbents prepared from the modified waste newspapers: A low-cost and available adsorbent, Microchem. J., 146, 2019, 1043-1053.

10.HARJA, M., RUSU, L., BUCUR, D., CIOCINTA, R.C., Fly ash derived zeolites as adsorbents for Ni removal from wastewater, Rev. Roum. Chim., 56, 2012, 587-593.

11.DAS, K.K., REDDY, R.C., BAGOJI, I. B., DAS, S., BAGALI, S., MULLUR, L., BIRADAR, M. S., Primary concept of nickel toxicity-an overview, J. Basic Clin. Physiol. Pharmacol., 30(2), 2018, 141-152.

12.BUEMA, G., CIMPEANU, S. M., SUTIMAN, D., BUCUR, R.D., RUSU, L., CRETESCU, I., HARJA, M., Lead removal from aqueous solution by bottom ash, J. Food Agric. Environ., 11(1), 2013, 1137-1141.

13.NOLI, F., KAPNISTI, M., BUEMA, G., HARJA, M., Retention of barium and europium radionuclides from aqueous solutions on ash-based sorbents by application of radiochemical techniques, Appl. Radiat. Isotopes, 116, 2016, 102-109.

14.PATESCU, R.E., SIMONESCU, C.M., ONOSE, C., BUSUIOC, T.L., PASARICA, D.E., DELEANU, C., Simultaneous Removal of Lead and Nickel Ions from Aqueous Synthetic Solutions by Chitosan Coated Cobalt Ferrite, Rev. Chim., 68(1), 2017, 1-5.

15.KAMEDA, T., TAKAIZUMI, M., KUMAGAI, S., SAITO, Y., YOSHIOKA, T., Adsorption of various metals by carboxymethyl- $\beta$-cyclodextrin-modified $\mathrm{ZnAl}$ layered double hydroxides, Appl. Clay Sci., 187, 2020,105479.

16.ZAHER, A., TAHA, M., FARGHALI, A.A., MAHMOUD, R.K., Zn/Fe LDH as a clay-like adsorbent for the removal of oxytetracycline from water: combining experimental results and molecular simulations to understand the removal mechanism, Env. Sci. Poll. Res., 2020, 27, 1225612269. 
17.SHEN, Z., ZHANG, Y., MCMILLAN, O., JIN, F., AL-TABBAA, A., Characteristics and mechanisms of nickel adsorption on biochars produced from wheat straw pellets and rice husk, Environ. Sci. Pollut. Res. Int., 24(14), 2017; 12809-12819.

18.BARTCZAK, P., NORMAN, M., KLAPISZEWSKI Ł., KARWANSKA, N., KAWALEC, M., BACZYNSKA, M., WYSOKOWSKI, M., ZDARTA, J., CIESIELCZYK, F., JESIONOWSKI, T., Removal of nickel(II) and lead(II) ions from aqueous solution using peat as a low-cost adsorbent: A kinetic and equilibrium study, Arab. J. Chem., 11(8), 2018, 1209-1222.

19.HARJA, M., BUEMA, G., SUTIMAN, D.M., CRETESCU, I., Removal of heavy metal ions from aqueous solutions using low-cost sorbents obtained from ash, Chem. Pap., 67(5), 2013, 497-508.

20.BELOVA, T.P., Adsorption of heavy metal ions $\left(\mathrm{Cu}^{2+,} \mathrm{Ni}^{2+} \mathrm{Co}^{2+}\right.$ and $\left.\mathrm{Fe}^{2+}\right)$ from aqueous solutions by natural zeolite, Heliyon, 5(9), 2019, e02320.

21.PAHLAVANZADEH, H., MOTAMEDI, M., Adsorption of Nickel, Ni(II), in Aqueous Solution by Modified Zeolite as a Cation-Exchange Adsorbent, J. Chem. Eng. Data, 65(1), 2020, 185-197.

22.CRETESCU, I., SOREANU, G., HARJA, M., A low-cost sorbent for removal of copper ions from wastewaters based on sawdust/fly ash mixture, Int. J. Env. Sci. Technol., 12, 2015, 1799-1810.

23.XUE, X., ZHANG, H., ZHANG, S., Preparation of MgAl LDHs Intercalated with Amines and Effect on Thermal Behavior for Poly(vinyl chloride), Adv. Mat. Physics Chem., 4(12), 2014, 258-266.

24.DINARI, M., MALLAKPOUR, S., Exfoliation and dispersion of nano-sized modified-LDH particles in poly(amide-imide)s containing N-trimellitylimido-L-methionine and 3,5-diaminoN(pyridin-3-yl)benzamide linkages, Polym. Bull., 72(5), 2015, 977-991.

25.EL-SAYED, M., ESHAQ, G., EIMETWALLY, A.E., Adsorption of heavy metals from aqueous solutions by Mg-Al-Zn mingled oxides adsorbent, Water Sci. Technol., 74(7), 2016, 1644-1657.

26.FIGUEREDO BENICIO, L.P., ALVARENGA SILVA, R., APARECIDA LOPES, J., EULALIO, D., MORAIS MENEZES dos SANTOS, R., de AQUINO, L.A., VERGUTZ, L., FERREIRA NOVAIS, R., da COSTA, L.M., GARCIA PINTO, F., TRONTO, J., Layered double hydroxides: nanomaterials for applications in agriculture, R. Bras. Ci. Solo, 39, 2015, p.1-13.

27.JAMHOUR, R.M.A.Q., ABABNEH, T.S., AL-RAWASHDEH, A.I., AL-MAZAIDEH, G.M., AL SHBOUL, T.M.A., JAZZAZ, T.M.A., Adsorption Isotherms and Kinetics of $\mathrm{Ni}(\mathrm{II})$ and $\mathrm{Pb}$ (II) Ions on New Layered Double Hydroxides-Nitrilotriacetate Composite in Aqueous Media, Adv. Analyt. Chem., 6(1), 2016, 17-33.

28.LI, P., ZHU, M., TIAN, Z., HAN, Y., ZHANG, Y., ZHOU, T., KANG, L., DAN, J., GUO, X., YU, F., WANG, Q., DAI, B., Two-Dimensional Layered Double Hydroxide Derived from Vermiculite Waste Water Supported Highly Dispersed Ni Nanoparticles for CO Methanation, Catalysts, 7(3), 2017, 79-89.

29.HUANG, X., YANG, X., LI, G. EZEH, C.I., SUN, C., SNAPE, C., Hybrid Two-step Preparation of Nanosized MgAl Layered Double Hydroxides for $\mathrm{CO}_{2}$ Adsorption, IntechOpen, London, 2019, 1-20. DOI: 10.5772/intechopen.86608.

30.BOUDAOUD, A., DJEDID, M., BENALIA, M., AD, C., BOUZAR, N., ELMSELLEM, H., Removal of nickel (II) and cadmium (II) ions from wastewater by palm fibers, Sci. Study Res.: Chem. Chem. Eng. Biotechnol. Food Ind., 18(4), 2017, 391 - 406.

31.HU, X., XUE, Y., LIU, L., ZENG, Y., LONG, L., Preparation and characterization of $\mathrm{Na}_{2} \mathrm{~S}-$ modified biochar for nickel removal, Environ. Sci. Pollut. Res., 25, 2018, 9887-9895.

32.OTGONJARGALL, E., NYAMSUREN, B., SURENJAV, E., BURMAA, G., TEMUUJIN, J., KHASBAATAR, D., Removal of Chromium from Aqueous Solution by Thermally Treated Mgal Layered Double Hydroxide, Ann .Civil Environ. Eng., 1, 2017, 001-008.

33.RAHMANIAN, O., DINARI, M., NEAMATI, S., Synthesis and characterization of citrate intercalated layered double hydroxide as a green adsorbent for $\mathrm{Ni}^{2+}$ and $\mathrm{Pb}^{2+}$ removal, Environ. Sci. Pollut. Res., 25, 2018, 36267-36277.

34.LIU, G., YANG, J., XU, X., HE, Z., Mg-Al Hydrotalcites Intercalated by Ethylenediaminetetra acetic Acid for Ni(II) Removal from Aqueous Solution, J. Chem. Eng., 64 (12), 2019, 5838-5846. 
35.MADDODI, S.A., ALALWANA, H.A., ALMINSHIDB, A.H., ABBAS, M.N., Isotherm and computational fluid dynamics analysis of nickel ion adsorption from aqueous solution using activated carbon, S. Afr. J. Chem. Eng., 32, 2020, 5-12.

36.JUMINA, PRIASTOMO, Y., SETIAWAN, H.R., MUTMAINAH, KURNIAWAN,Y.S., OHTO, K., Simultaneous removal of lead(II), chromium(III), and copper(II) heavy metal ions through an adsorption process using C-phenylcalix [4] pyrogallolarene material, J. Environ. Chem. Eng., 8(4), 103971.

37.MALEKI, S., KARIMI-JASHNI, A., Optimization of Ni(II) adsorption onto Cloisite $\mathrm{Na}^{+}$clay using response surface methodology, Chemosphere, 246, 2020, 125710.

38.MOHAMMED, A.A., NAJIM, A.A., AL-MUSAWI, T.J., ALWARED, A.I., Adsorptive performance of a mixture of three nonliving algae classes for nickel remediation in synthesized wastewater, J. Environ. Health Sci. Eng., 17(2), 2019, 529-538.

39.TRAN, L.T., TRAN, H.V., LE, T.D., BACH, G.L., TRAN, L.D., Studying Ni(II) Adsorption of Magnetite/Graphene Oxide/Chitosan Nanocomposite, Adv. Polymer Technol., 2019, Article ID 8124351

40.LIHAREVA, N., DIMOWA, L., PETROV, O., TZVETANOVA, Y., ATANASOVAVLADIMIROVA, S., Study of the kinetics and mechanism of $\mathrm{Sr}^{2+}$ sorption by clinoptilolite, $J$. Radioanal. Nucl. Chem., 321, 2019, 31-38.

41.SHI, M., ZHAO, Z., SONG, Y., XU, M., LI, J., YAO, L., A novel heat-treated humic acid/ MgAllayered double hydroxide composite for efficient removal of cadmium: Fabrication, performance and mechanisms, Appl. Clay Sci., 187, 2020, 105482.

42.ZHANG, L., LOAICIGA, H.A., XU, M., DU, C., DU, Y., Kinetics and Mechanisms of Phosphorus Adsorption in Soils from Diverse Ecological Zones in the Source Area of a Drinking-Water Reservoir, Int. J. Environ. Res. Public Health, 12, 2015, 14312-14326. doi:10.3390/ijerph121114312.

$\overline{\text { Manuscript received: } 18.05 .2020}$ 